\title{
Cotranscriptional effect of a premature termination codon revealed by live-cell imaging
}

\author{
VALERIA DE TURRIS, ${ }^{1}$ PAMELA NICHOLSON, ${ }^{2}$ RODOLFO ZAMUDIO OROZCO, ${ }^{2}$ ROBERT H. SINGER, ${ }^{1,3}$ \\ and OLIVER MÜHLEMANN ${ }^{2,3}$ \\ ${ }^{1}$ Albert Einstein College of Medicine, Bronx, New York 10461, USA \\ ${ }^{2}$ Department of Chemistry and Biochemistry, University of Bern, CH-3012 Bern, Switzerland
}

\begin{abstract}
Aberrant mRNAs with premature translation termination codons (PTCs) are recognized and eliminated by the nonsensemediated mRNA decay (NMD) pathway in eukaryotes. We employed a novel live-cell imaging approach to investigate the kinetics of mRNA synthesis and release at the transcription site of PTC-containing (PTC+) and PTC-free (PTC-) immunoglobulin- $\mu$ reporter genes. Fluorescence recovery after photobleaching (FRAP) and photoconversion analyses revealed that PTC+ transcripts are specifically retained at the transcription site. Remarkably, the retained PTC+ transcripts are mainly unspliced, and this RNA retention is dependent upon two important NMD factors, UPF1 and SMG6, since their depletion led to the release of the PTC+ transcripts. Finally, ChIP analysis showed a physical association of UPF1 and SMG6 with both the PTC+ and the PTC - reporter genes in vivo. Collectively, our data support a mechanism for regulation of PTC+ transcripts at the transcription site.
\end{abstract}

Keywords: live-cell imaging; NMD; retention; splicing; UPF1; SMG6

\section{INTRODUCTION}

Nonsense-mediated mRNA decay (NMD) is a eukaryotic translation-dependent mechanism that recognizes and degrades mRNAs with a termination codon (TC) in an unfavorable environment for efficient translation termination (Amrani et al. 2006; Nicholson et al. 2010). Long 3' untranslated regions ( $3^{\prime}$ UTRs), upstream open reading frames (uORFs), or introns located $>50$ nucleotides downstream from the TC are examples of mRNA features that can trigger NMD, but exactly how NMD substrates are distinguished from normal mRNAs is not fully understood (Rebbapragada and LykkeAndersen 2009; Nicholson et al. 2010). Aberrant mRNAs with truncated open reading frames usually fulfill one or several of these NMD-inducing features. Therefore, NMD functions as an important quality control mechanism that prevents the production of potentially deleterious C-terminally truncated proteins (Isken and Maquat 2007). However, genome-wide transcriptome profiling studies have revealed that many physiological mRNAs are also NMD

\footnotetext{
${ }^{3}$ Corresponding authors.

E-mail oliver.muehlemann@dcb.unibe.ch.

E-mail robert.singer@einstein.yu.edu.

Article published online ahead of print. Article and publication date are at http://www.rnajournal.org/cgi/doi/10.1261/rna.02918111.
}

substrates, manifesting an additional role of NMD in the post-transcriptional regulation of gene expression (Rehwinkel et al. 2006).

The NMD pathway in human cells includes the evolutionarily conserved proteins UPF1, UPF2, UPF3A, and UPF3B, as well as additional metazoan-specific factors, such as SMG1, SMG5, SMG6, SMG7, NAG, DHX34, SMG8, and SMG9 (Nicholson et al. 2010). The exact spatial and temporal order in which these proteins interact with one another and with the terminating ribosome is not known and is the subject of intense study. Recent data suggest that UPF2- and UPF3independent NMD pathways may exist (Chan et al. 2007; Ivanov et al. 2008), whereas the nucleic acid-dependent ATPase and helicase UPF1 and the endonuclease SMG6 appear to be indispensable for NMD function in mammalian cells. Importantly, UPF1 is a phosphoprotein that can be phosphorylated by SMG1, a member of the phosphatidylinositol 3-kinase-related protein kinase (PIKK) family (Nicholson et al. 2010). Interestingly, UPF1 and SMG6 have also been shown to localize to telomeres, and their siRNA-mediated depletion leads to accumulation of telomeric repeat-containing RNA (TERRA) and telomere damage (Azzalin and Lingner 2006b; Azzalin et al. 2007). Furthermore, UPF1 is known to be involved in several RNA metabolism pathways, often in nuclear processes, namely in cell cycle progression, DNA 
replication, and DNA repair (Azzalin and Lingner 2006a; Nicholson et al. 2010).

There is conflicting evidence as to whether NMD occurs in the nucleus or in the cytoplasm. Due to its well-documented dependence on translation, it has generally been assumed that NMD must occur in the cytoplasm (Bohnsack et al. 2002). In support of this, expression of polypeptides designed to inhibit interactions between several NMD factors efficiently inhibited NMD when these polypeptides were expressed in the cytoplasm but not when they were expressed in the nucleus (Singh et al. 2007). On the other hand, aminoacylated tRNAs and many translation factors have been detected in nuclei, and there are ample reports providing evidence for nuclear translation (Lund and Dahlberg 1998; Iborra et al. 2001; Brogna et al. 2002; Iborra et al. 2004a). In addition, NMD is thought to be confined to transcripts bound to the nuclear cap binding complex factor CBP80 (Ishigaki et al. 2001; Chiu et al. 2004; Matsuda et al. 2007), and many premature translation termination codon-containing (PTC+) reporter mRNAs are degraded prior to their release from the nucleus (Cheng and Maquat 1993; Belgrader et al. 1994; Carter et al. 1996; Kessler and Chasin 1996; Zhang et al. 1998; Wang et al. 2002b; Bhalla et al. 2009). Furthermore, inhibition of mRNA export did not prevent NMD of a PTC+ TCR- $\beta$ reporter transcript (Buhler et al. 2002). Moreover, examples have been reported where the presence of a PTC in the transcript affects nuclear processes such as pre-mRNA splicing and transcription (Dietz and Kendzior 1994; Lozano et al. 1994; Aoufouchi et al. 1996; Muhlemann et al. 2001; Li et al. 2002; Wang et al. 2002a; Buhler et al. 2005). In particular, by combining biochemical methods and fluorescent in situ hybridization (FISH), pre-mRNA accumulation at the transcription site (TS) of PTC+ endogenous Ig- $\mu$ genes in mouse hybridoma cells has been observed (Muhlemann et al. 2001). Integration of Ig- $\mu$ minigene constructs derived from these mouse hybridoma Ig- $\mu$ genes into HeLa cells led to a PTC-specific, UPF1- and translationdependent inhibition of the transcription of these minigenes (Buhler et al. 2005; Stalder and Muhlemann 2007). Recently it has been observed that SMG6, but not SMG5 or SMG7, is also important for this previously reported PTC-specific inhibition of transcription (P Nicholson and O Mühlemann, unpubl.). These results suggested an NMD-related function at the site of transcription.

In order to investigate how the mRNA reading frame is able to influence events at or near the site of transcription, we took advantage of a live-cell imaging approach of single cells to gain insight into kinetic events that occur in this RNA quality control pathway. This technique allowed us to show that a mechanism involving the NMD factors UPF1 and SMG6 affects the release of PTC+ transcripts that accumulate as unspliced RNA at the TS. We have also observed that UPF1 and SMG6 can physically associate with the transcription sites of both PTC - and PTC + Ig- $\mu$ minigenes, where they are likely to be playing an important role in recognizing and preventing $\mathrm{PTC}+$ pre-mRNAs from subsequent splicing and export by retaining them at the TS. Hence, these results suggest that the pathway of NMD can act in the nucleus at the site of transcription as well as post-transcriptionally in the cytoplasm to collectively reduce the abundance of PTCcontaining pre-mRNA and mRNAs in the cell.

\section{RESULTS}

\section{The presence of a PTC leads to the loss of mini $\mu$ mRNA in the cytoplasm and retention of unspliced RNA at the TS}

We developed an in vivo approach to measure transcription in real time on the single-cell level and to monitor differences in behavior between a PTC- (wild type) and a PTC+ gene. In particular, we utilized the previously characterized Ig- $\mu$ minigene constructs (Buhler et al. 2004). The mini $\mu$ WT construct was derived from the productively rearranged Ig- $\mu$ gene of the hybridoma cell line Sp6 (Ochi et al. 1983), which produces IgM against the hapten 2,4,6-trinitrophenyl (Kohler and Milstein 1976), whereas the mini $\mu$ ter310 harbors a single point mutation that introduces a PTC at codon 310 in the $\mathrm{C} 2$ exon (Fig. 1A). We generated modified versions of the Ig- $\mu$ minigenes, exploiting the MS2 system (Bertrand et al. 1998; Darzacq et al. 2007). The insertion of 24 MS2 binding sites (MBS) in the 3' UTR allowed for the visualization of transcription sites in vivo upon binding of these stem-loops by the MS2 coat protein (MCP) fused to a fluorescent protein (Fig. 1A). The resulting reporter genes were transfected into human U2OS cells, and monoclonal lines carrying stable integrations of the PTC - and the PTC+ MBS variants were generated. Stable transfection results in the integration of multiple copies of the gene construct at one genomic locus, which is required for subsequent live-cell imaging of active transcription sites (Darzacq et al. 2005). Several clones, each carrying stable integrations of either the PTC- and the PTC+ MBS, were selected that contained these arrays in a single location in the genome and had similar copy numbers ( $\mu$ wtMBS and $\mu$ ter310-MBS) (Supplemental Fig. S1).

In order to characterize gene expression and transcript distribution in these clones, we performed RNA FISH using probes against the MBS region, allowing detection of transcribed RNAs. This analysis showed a single transcription site in the nucleus and multiple mRNA molecules distributed in the cytoplasm of $\mu \mathrm{wt}-\mathrm{MBS}$ cells (Fig. 1B, $\mu$ wt-MBS panels). In contrast, no mRNA was detected in the cytoplasm of the $\mu$ ter310-MBS cells, and only the transcription site was visible (Fig. 1B, $\mu$ ter310-MBS panels). The absence of transcripts in the cytoplasm assessed by FISH, together with low steady-state RNA levels detected by RT-qPCR analysis (Supplemental Fig. S2A), confirmed that the PTC+ transcripts had been subjected to NMD. Interestingly, the transcription sites were, on average, brighter in the $\mu$ ter310-MBS than in the $\mu$ wt-MBS (Fig. 1B). Previously, brighter transcription sites have also 
A

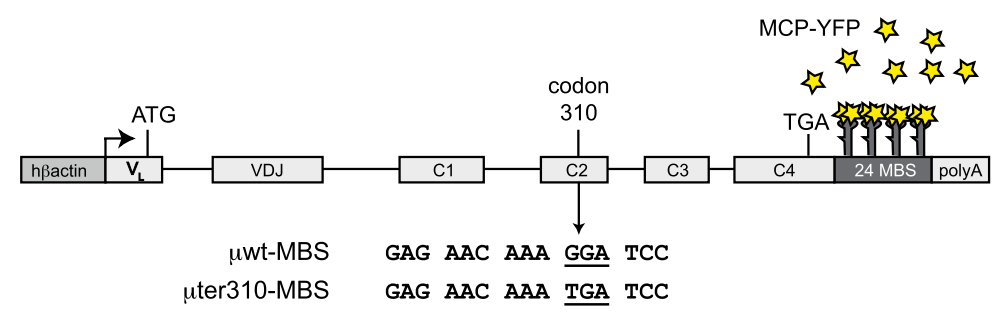

B

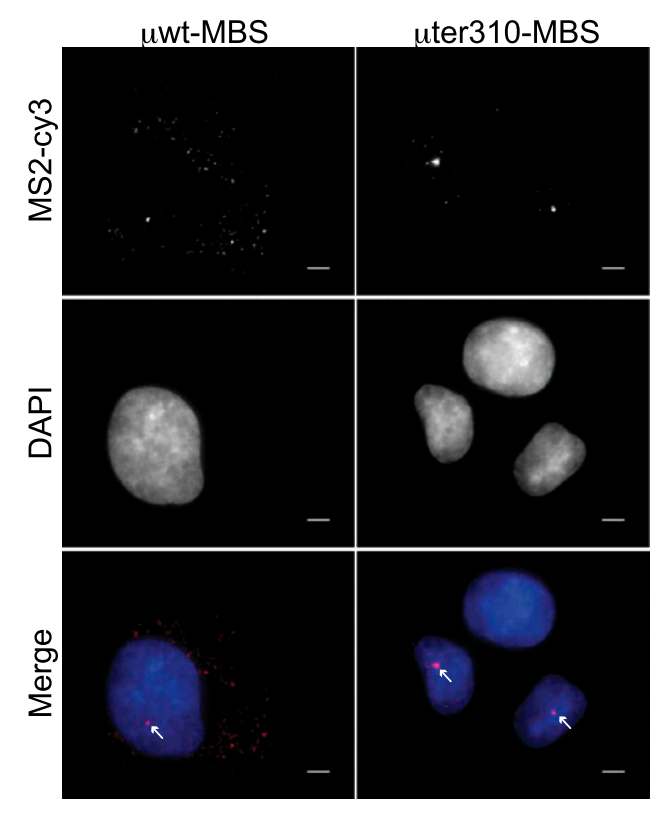

C

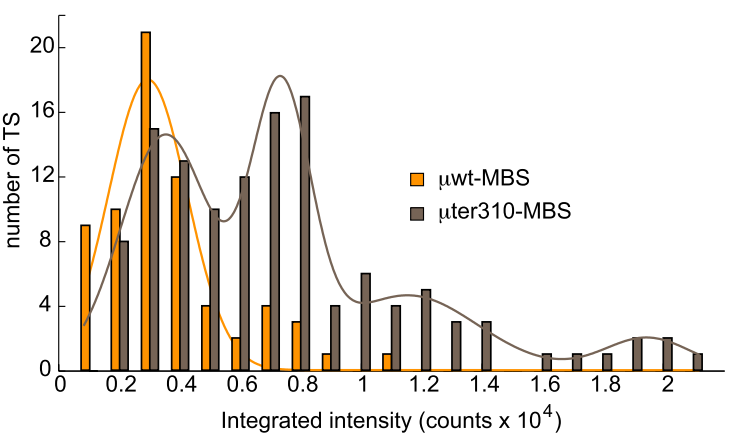

D

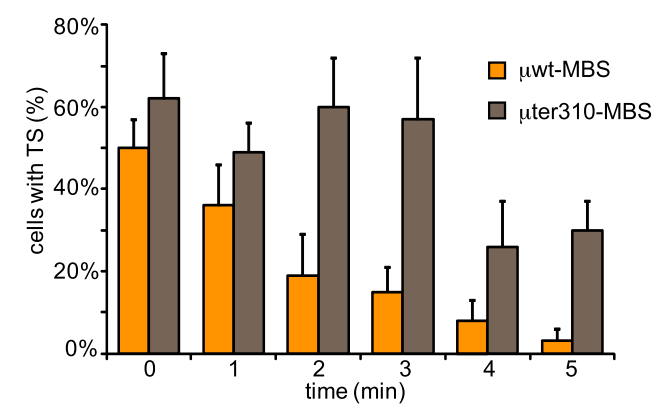

FIGURE 1. The presence of a PTC triggers transcript retention at the transcription site. (A) Schematic representation of the mini $\mu$ genes stably inserted in U2OS cells either with the wild-type sequence or with a single point mutation generating a PTC at amino acid 310 (TGA, arrow). Clonal cell lines express the WT ( $\mu$ wt-MBS) or the PTC+ mini $\mu$ gene ( $\mu$ ter310-MBS); see also Supplemental Fig. S1. Transcription is driven by the human $\beta$-actin promoter (hßactin). Twenty-four MS2 binding sites (MBS) were inserted in the $3^{\prime}$ UTR, allowing the specific tethering of the MS2 coat protein fused to yellow fluorescent protein (MCP-YFP). (B) RNA FISH using Cy3-labeled probes against the MBS region (MS2-cy3). DAPI staining marks the nuclear region. White arrows depict transcription sites. Images are maximal projections from $4 \mu \mathrm{m}$ stacks. Scale bars, 4 $\mu \mathrm{m}$. (C) Transcription site (TS) intensities from the FISH data were quantified and plotted, and their distribution was Gaussian-fitted in MatLab. (Orange) $\mu \mathrm{wt}$-MBS, (brown) $\mu$ ter310-MBS. (D) Time course of actinomycin D treatments demonstrating post-transcriptional retention of transcripts at the TS. Average values and standard deviations of three experiments are shown.

been observed in hybridoma cells expressing a PTC + Ig- $\mu$ gene (Muhlemann et al. 2001), indicating that accumulation of PTC+ transcripts at the TS might be a general feature of Ig- $\mu$ genes.

The brighter TS suggested that transcripts were being retained at the locus in the $\mu$ ter310-MBS. Therefore, we quantified the intensity of the TS from the FISH data using custom-made software (Thompson et al. 2002). The analysis showed that the PTC+ TS was, on average, twice as bright as the wild-type TS. Importantly, a more detailed examination showed that the intensity distribution fitted a single Gaussian distribution for the $\mu$ wt-MBS, whereas the $\mu$ ter310-MBS fitted multiple Gaussian distributions. The first peak obtained from the PTC+ transcripts overlaps with the peak obtained from wild-type transcripts, while the additional PTC+ peaks were shifted to higher fluorescent intensities (from 2 to 5.5 times brighter) (Fig. 1C).

To test if the presence of a PTC leads to retention of the RNA at the TS, we performed FISH with MBS probes after transcription inhibition with actinomycin $\mathrm{D}$ for short periods to avoid degradation. The rapid loss of visible TS in the $\mu \mathrm{wt}-$ MBS cells demonstrated that all the transcripts present at the site were efficiently released into the nucleoplasm upon termination. In contrast, the PTC+ transcripts persisted significantly longer at the TS (Fig. 1D), indicating an impaired dispersion after transcription termination. Collectively, these 
results confirmed that the presence of a PTC in the mini $\mu$ transcripts slows down the kinetics of transcript release or that it elicits retention of a fraction of the PTC+ transcripts (see below).

To further characterize whether these transcripts were processed, we performed RNA FISH using multiple probes designed to discriminate the spliced from the unspliced mini $\mu$ transcripts (Fig. $2 \mathrm{~A})$. In the cells expressing PTC- mini $\mu$, both RNA species were detected overlapping or adjacent to each other at the TS of most cells, consistent with splicing occurring cotranscriptionally (Fig. 2B, $\mu w t-M B S$ panels; Pandit et al. 2008). Spliced PTC- mini $\mu$ RNAs were observed throughout the nucleoplasm and cytoplasm. In striking contrast, very few spliced transcripts could be detected at the PTC+ TS in $\mu$ ter310-MBS, whereas unspliced RNAs were visible at every TS (Fig. 2B, $\mu$ ter310-MBS panels). Quantification of the percentage of TSs showing the relative amounts of each species confirmed that the presence of the PTC dramatically increased the amount of unspliced transcripts at the TS (Fig. 2C). This result suggested that a PTC in the mini $\mu$ pre-mRNA strongly inhibited splicing. Furthermore, it indicates that the TS-retained PTC+ RNA detected with the MBS probe in Figure 1 was largely unspliced.

\section{Dynamics at the transcription site are affected by a PTC}

To investigate real-time dynamics of mini $\mu$ RNA at the TS of $\mu w t-M B S$ and $\mu$ ter310-MBS, we performed fluorescence recovery after photobleaching (FRAP). Cell lines stably expressing the MCP-YFP fusion protein were generated by lentivirus infection (Mostoslavsky et al. 2006). Unlike transient transfections, this allowed more uniform expression levels within and among experiments. The MS2 and the tandem gene array amplified the RNA signal sufficiently to measure the recovery. During live-cell imaging, the transcription sites were easily recognized as bright spots in the nucleus. As with the FISH experiments, mRNAs were not visible in the cytoplasm of the PTC+

B

C
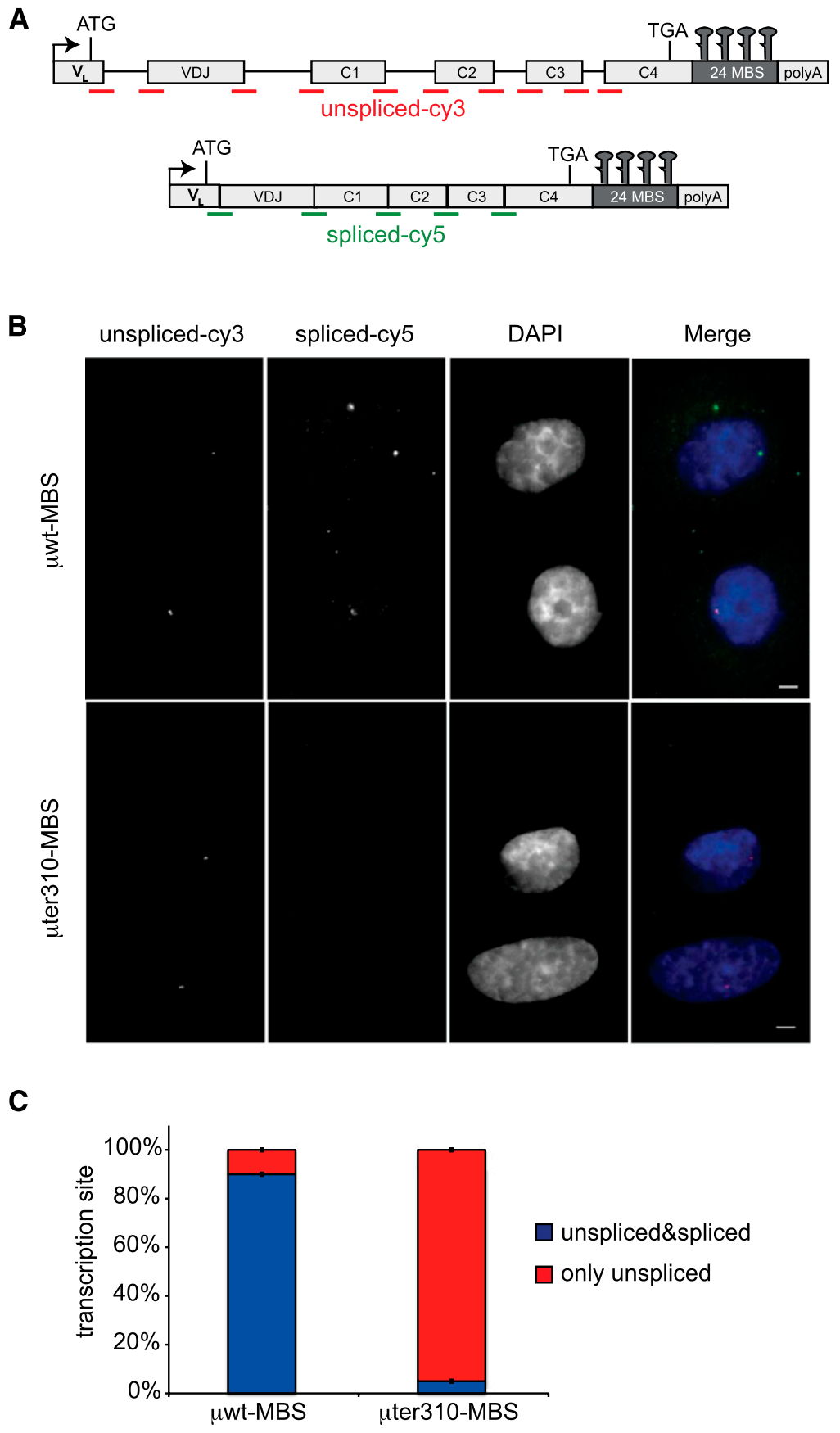

FIGURE 2. Retained transcripts are mostly unspliced. (A) Schematic representation of the unspliced and spliced transcripts depicting the positions of the Cy3 and Cy5 probes used in $B$. $(B)$ RNA FISH using a mixture of probes against the 10 intron-exon junctions (unspliced-cy3) and the 5 exon-exon junctions (spliced-cy5) in $\mu$ wt-MBS and $\mu$ ter310-MBS cells. DAPI marks the nuclear region. Images are maximal projections from $4 \mu \mathrm{m}$ stacks. Scale bars, $4 \mu \mathrm{m} .(C)$ Quantification of transcription sites with only unspliced (red) or both spliced and unspliced (blue) RNA signals in $\mu w t-M B S$ and $\mu$ ter310-MBS. Average values and standard deviations of two experiments are shown.

mini $\mu$-expressing cells, in contrast to wild-type cells (Fig. 3, cf. panels $\mathrm{A}$ and $\mathrm{H}$ ).

Transcription was monitored by the recovery of newly synthesized MS2 binding sites during elongation, after 


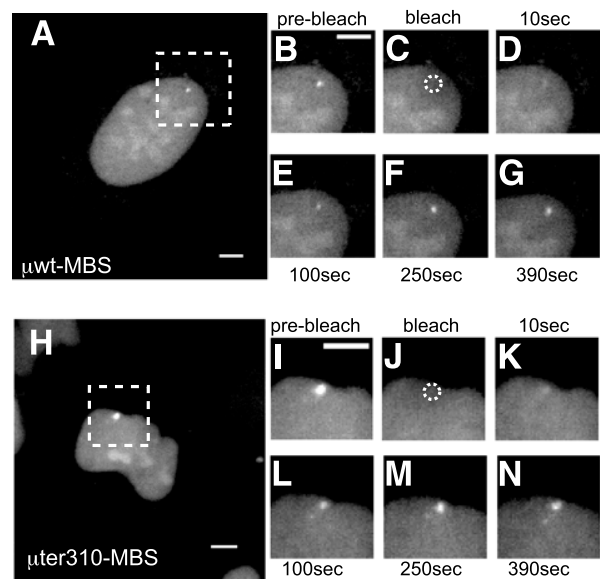

0

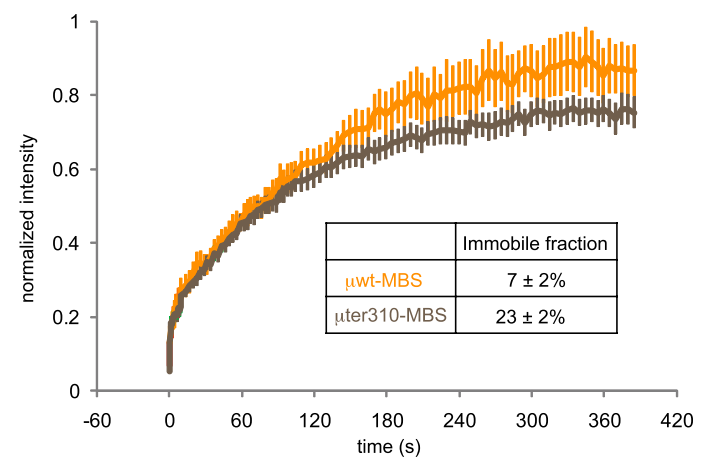

FIGURE 3. FRAP experiments detect impaired recovery at the $\mu$ ter310-MBS transcription site (TS). FRAP experiments were performed with $\mu$ wt-MBS $(A-G)$ and $\mu$ ter310-MBS cells $(H-N)$ expressing MCP-YFP (see also Supplemental Movies S1 and S2). In $A$ and $H$, dashed rectangles highlight the regions shown in the recovery time series. In $B, C$ and $I, J$, TSs were bleached ( $488 \mathrm{~nm}$, dashed circles) and monitored as indicated ( $D-G$ and $K-N$; note the brightness of $I$ does not recover completely). Scale bars, $5 \mu \mathrm{m}$. (O) Recovery curves from the data analysis as mean fluorescence intensities +/-SEM (20-30 experiments for each). The table summarizes the immobile RNA fractions. See also Supplemental Fig. S3.

photobleaching of the MCP-YFP labeled transcripts at the transcription sites (Fig. 3B-G,I-N). Images were analyzed with a tracking algorithm that enabled us to follow the transcription site position over the entire time frame of the experiments (6-7 min) (Supplemental Movies S1 and S2). The resulting recovery curves are shown in Fig. 3O. Importantly, the analysis of the FRAP experiments highlighted the presence of an immobile fraction that did not recover during the course of the experiment. In the case of $\mu$ ter310-MBS, this immobile fraction is over threefold that of the $\mu$ wt-MBS (Fig. 3O). This supports the retention hypothesis, since these bleached transcripts did not leave the TS and therefore contributed a "dark" fraction (23\%) during the recovery. Previous work has shown that lengthening of the $3^{\prime}$ UTR can trigger a moderate NMD response (Buhler et al. 2006); the small immobile fraction measured for $\mu \mathrm{wt}-\mathrm{MBS}(7 \%)$ probably represents such a basal NMD effect triggered by the insertion of the 1.2-kb-long MBS into the 3' UTR of the mini $\mu$ gene (Eberle et al. 2008). Other monoclonal cell lines confirmed that these observations on transcript retention were specific to the genes and not the cell lines (Supplemental Fig. S3).

\section{Depletion of the NMD factors SMG6 and UPF1 restores transcript release from the transcription site}

To test whether the transcript retention observed by FISH and FRAP was dependent on the NMD pathway, we performed RNAi-mediated depletion of SMG6, the endonuclease responsible for the primary cleavage during the NMD degradation process (Huntzinger et al. 2008; Eberle et al. 2009). The SMG6 knockdown was verified by Western blotting and RT-qPCR (Fig. 4A; Supplemental Fig. S2C, respectively). Upon knockdown of SMG6, PTC+ transcripts became detectable in the cytoplasm (Fig. 4B, $\mu$ ter310-MBS $\triangle$ SMG6 panels) but not in cells expressing a control shRNA (Fig. 4B, $\mu$ ter310-MBS scr panels). This confirmed that the absence of PTC + transcripts in the cytoplasm of $\mu$ ter310-MBS cells was not due to defective processing or export but rather due to a NMD-specific effect. Conversely, depletion of SMG6 in the $\mu w t-M B S$ cells did not reveal a significant change in the cellular distribution of the PTC- transcripts (Fig. 4B; Supplemental Fig. S2B).

Since FISH analysis demonstrated that depletion of SMG6 restored the presence of the PTC+ transcripts in the cytoplasm, we hypothesized that retention at the TS would also be affected. In agreement with this, FRAP on the $\mu$ ter310MBS cells after SMG6 knockdown showed complete recovery of the TS; the immobile fraction had disappeared (Fig. 4C). Similarly, the small immobile fraction detected at the TS in untreated $\mu \mathrm{wt}-\mathrm{MBS}$ was eliminated upon depletion of SMG6 (Fig. 4D). In keeping with the FISH results, this loss of the immobile fraction was not observed in $\mu$ ter310-MBS or $\mu$ wtMBS expressing the control shRNA (data not shown). Altogether, these experiments indicated that the retention of PTC+ mini $\mu$ RNA at the transcription locus was consistent with NMD since it required the NMD factor SMG6.

To further corroborate that the NMD pathway plays a role in transcription kinetics, we performed an RNAi-mediated knockdown of another essential component of the NMD pathway, the group I helicase and nucleic acid-dependent ATPase, UPF1. The UPF1 knockdown was monitored by Western blotting and RT-qPCR (Fig. 5A; Supplemental Fig. S2D, respectively). As with the knockdown of SMG6, FISH analysis showed a normal distribution in the cytoplasm for both wild type and PTC+ transcripts, demonstrating the failure of the NMD response upon depletion of UPF1 (Fig. 5B; Supplemental Fig. S2B). Furthermore, $\mu$ ter310-MBS $\triangle \mathrm{UPF} 1$ showed a complete fluorescence recovery after photobleaching (Fig. 5C). The observations that the retention of PTC+ transcripts requires UPF1 and SMG6 indicate that the NMD pathway also acts at the TS. The small immobile 
A
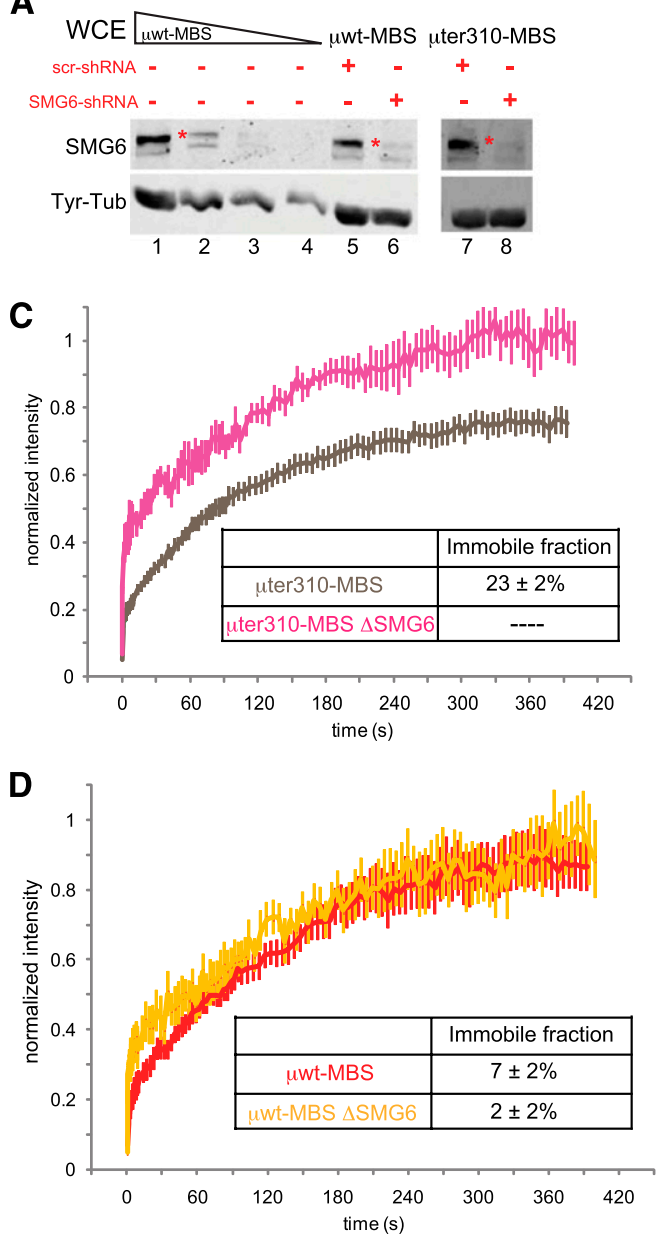

B
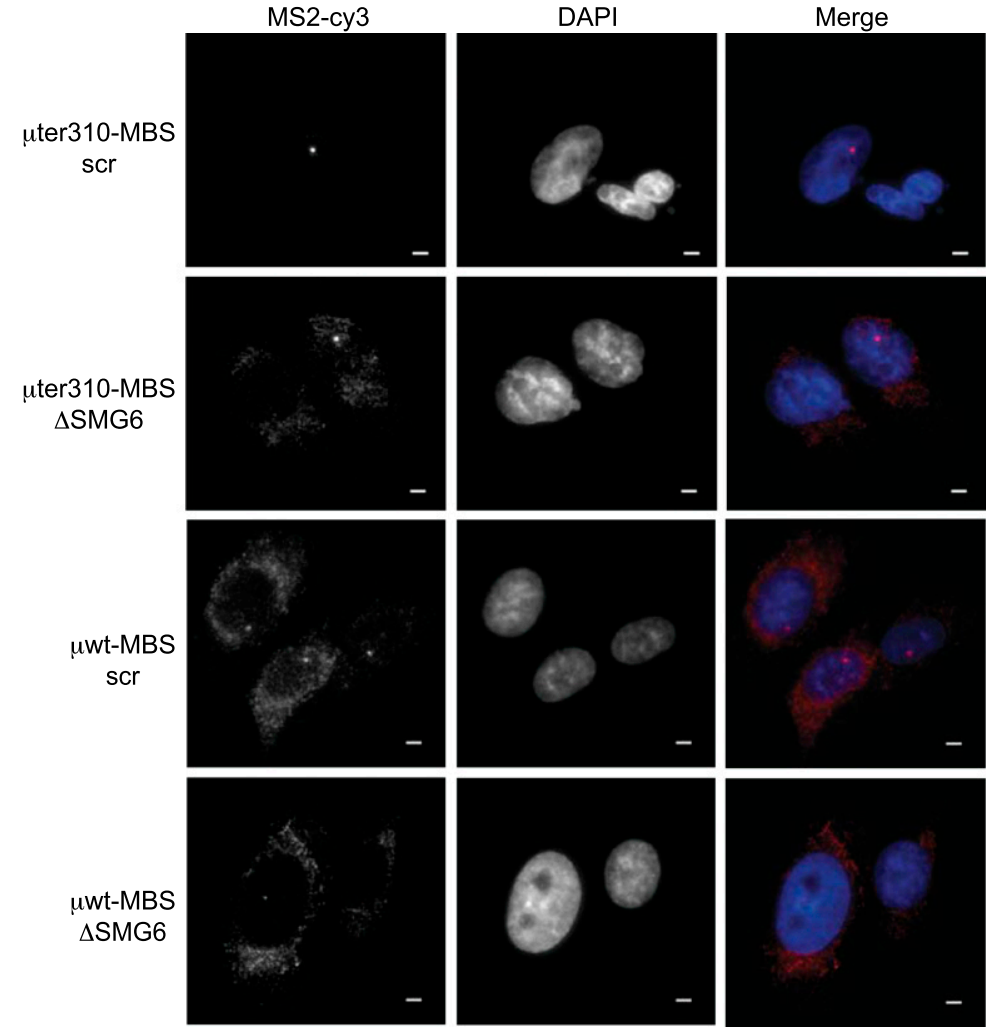

FIGURE 4. SMG6 knockdown restores PTC+ transcript release from the TS and its distribution in the cytoplasm. FISH was performed as in Figure 1B. (A) Western blot monitoring SMG6 protein levels in whole cell extract (WCE). The asterisks ${ }^{*}$ ) mark the SMG6-specific band. Control WCE (-) from $\mu \mathrm{wt}$-MBS (equivalent cells) and threefold serial dilutions of the untreated cells were loaded in lanes $1-4$. WCE from $\mu \mathrm{wt}-\mathrm{MBS}$ (lanes 5,6) and $\mu$ ter310-MBS cells (lanes 7,8) expressing scrambled-shRNA (scr-shRNA) or SMG6-targeting shRNA (SMG6-shRNA) were analyzed. Tyrosine-Tubulin (Tyr-Tub) was used as loading control (see also Supplemental Fig. S2). (B) Depletion of SMG6 leads to an accumulation of the PTC+ transcripts in the cytoplasm of $\mu$ ter310-MBS ( $\Delta$ SMG6, second row). SMG6 knockdown did not affect the cellular distribution of PTC - transcripts in $\mu$ wt-MBS ( $\mu$ wt-MBS $\Delta$ SMG6, fourth row). Scrambled shRNA (scr): first and third rows. Scale bars, $4 \mu \mathrm{m}$. $(C, D)$ Analysis of FRAP in SMG6-depleted cells shown as mean fluorescence intensity $+/-\operatorname{SEM}(n=10)$. $(C) \mu$ ter310-MBS before (brown) and after (pink) SMG6 knockdown. (D) $\mu$ wt-MBS before (red) and after (yellow) SMG6 knockdown. The table shows that the immobile fraction decreases upon SMG6 depletion.

fraction also disappeared in $\mu w t-M B S \triangle U P F 1$, but, unexpectedly, the profile of the recovery curve suggested an additional modification in the transcription kinetics that was not observed either with depletion of SMG6 nor in $\mu$ ter310MBS $\triangle$ UPF1 cells (Figs. 4D, 5D). Since fluorescence recovery during FRAP is based on RNA polymerases transcribing new binding sites, transcription elongation is the major component accounting for the recovery. The apparent change in the pol II elongation rate in response to UPF1 knockdown can be more easily appreciated after elimination of the immobile fraction from the recovery curve by normalization (Supplemental Fig. S4). Upon depletion of UPF1, $\mu$ ter310-MBS cells had similar elongation kinetics (Supplemental Fig. S4A), but in the WT, the half-recovery was faster (26 sec compared to
$50 \mathrm{sec}$ ), implying that elongation speed had doubled (Supplemental Fig. S4B). Therefore, our data suggest an additional role of UPF1 in the Ig- $\mu$ transcription regulation (see Discussion).

\section{UPF1 is required for retention of the PTC $+\operatorname{mini} \mu$ transcript at the TS}

To further dissect the UPF1-dependent alterations in PTC+ and PTC- mini $\mu$ transcript kinetics at the TS, we exploited the photo-convertible MCP-Dendra2 system, which allowed us to separate transcript elongation from termination and release. Dendra2 is a green-to-red photoswitchable fluorescent protein that can be excited in the green channel and, 
A
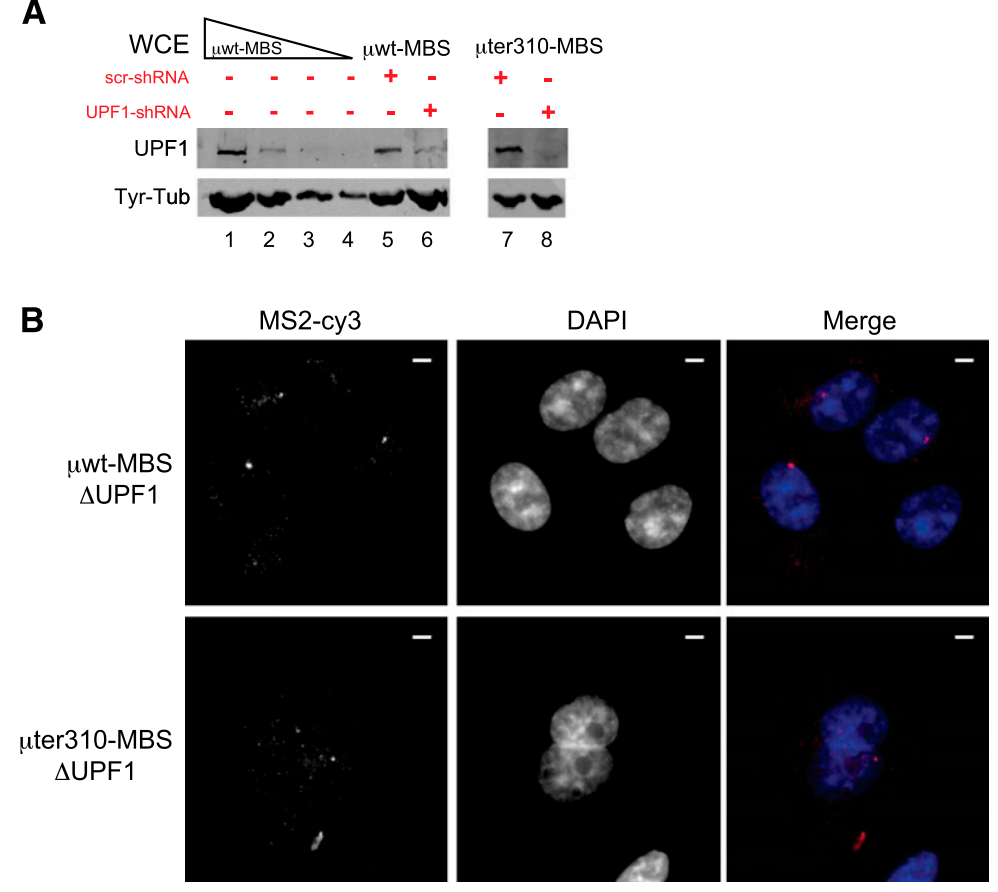

C

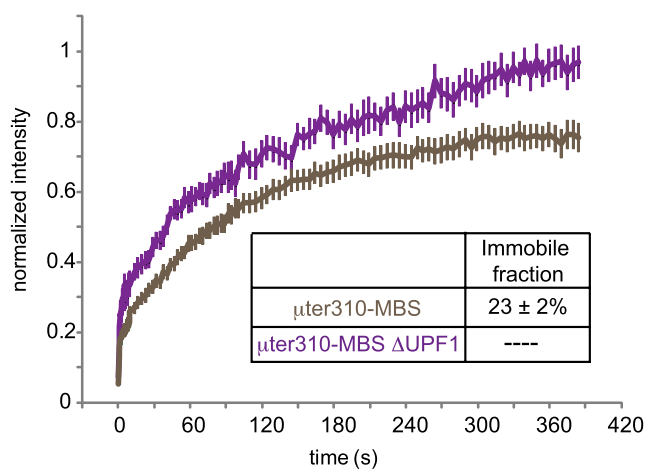

D

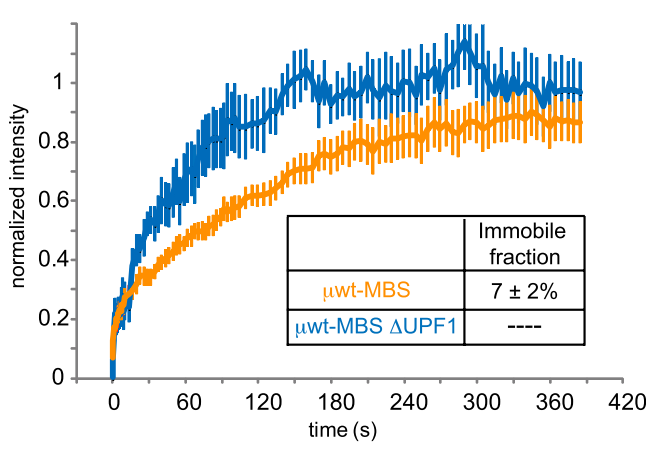

FIGURE 5. Knockdown of UPF1 affects transcription kinetics. (A) Western blot monitoring UPF1 protein levels in whole cell extract (WCE). Control WCE (-) from $\mu$ wt-MBS (equivalent cells) and threefold serial dilutions of the untreated cells were loaded in lanes 1-4. WCE from $\mu w t-$ MBS (lanes 5,6) and $\mu$ ter310-MBS cells (lanes 7,8) expressing scrambled-shRNA (scr-shRNA) or UPF1-targeting shRNA (UPF1-shRNA) were analyzed. Tyrosine-Tubulin (Tyr-Tub) served as loading control (see also Supplemental Fig. S2). (B) FISH performed as in Figure 1B. Compared to nontreated cells (Fig. 1B) and control knockdowns (Fig. 4A, scr), PTC+ transcripts in $\mu$ ter310-MBS $\Delta$ UPF1 accumulated in the cytoplasm, whereas no change in PTC - transcript distribution was visible in $\mu$ wt-MBS $\Delta$ UPF1 cells. Scale bars, $4 \mu m$. $(C, D)$ FRAP after UPF1 knockdown (mean fluorescence intensity $+/-$ SEM; $n=10$ ). (C) Recovery in $\mu$ ter310-MBS before (brown) and after (purple) UPF1 knockdown. (D) Recovery in $\mu w t-M B S$ before (orange) and after (blue) UPF1 knockdown. The table shows the disappearance of immobile fractions upon UPF1 depletion. Also see Supplemental Figure S4.

after irreversible photoactivation by a short $405-\mathrm{nm}$ laser pulse, in the red channel (Gurskaya et al. 2006). The photoswitch converts previously transcribed MCP-labeled mRNAs from green to red enabling the transcript release process to be assessed independently of the elongation. By monitoring the disappearance of the converted red signal, we were able to assess the termination and release kinetics. We generated $\mu w t-M B S$ and $\mu$ ter310-MBS cell lines stably expressing a MCP-Dendra2 fusion protein ( $\mu$ wt-MBS-Dendra and $\mu$ ter310MBS-Dendra, respectively). These experiments were performed on a wide-field microscope equipped with 405-, 488-, and 543-nm lasers and a dual-view EMCCD camera to allow photoactivation of a small region and simultaneous acquisition of the whole field in the green and red channels (see Materials and Methods).

We speculated that photoconversion would highlight the retained RNA fraction at the $\mu$ ter310-MBS-Dendra TS and that depletion of UPF1 would affect this fraction while leaving the release of PTC - transcripts unaltered. Figure 6A-D shows frames of the entire photoconversion time series (see also 

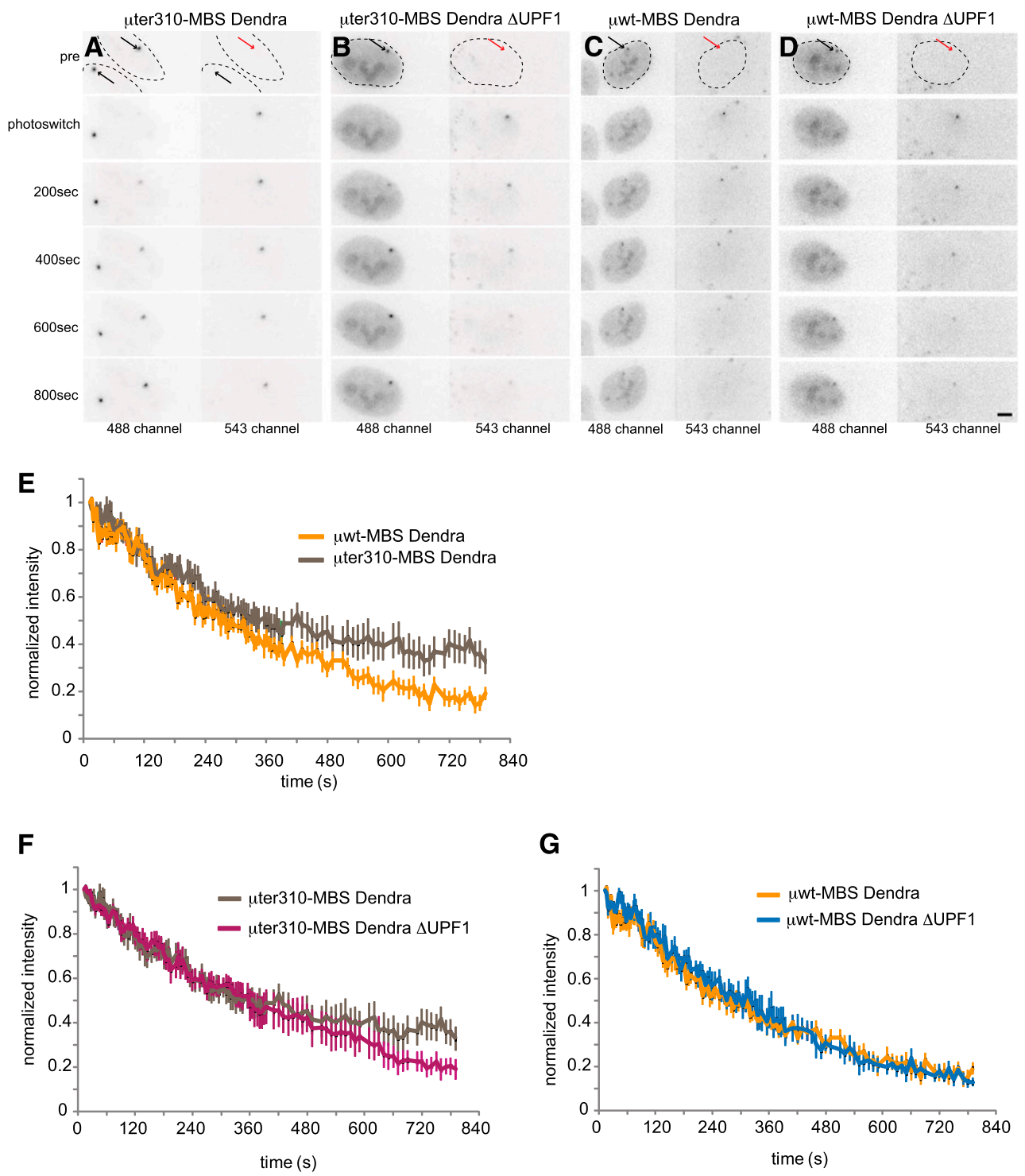

FIGURE 6. UPF1 depletion abolishes PTC+ mRNA retention but does not affect release of the PTC- mRNA. (A-D) MCP-Dendra2 photoconversion in untreated cells $(A, C)$ and after UPF1 depletion $(B, D)$. Left columns are the 488-nm excitation. Right columns are the 543 channel excitation. Pre: (black arrows) TS before activation, (red arrows) expected positions of photoswitched TSs in the red channel. Dashed lines denote the perimeter of the nucleus. After the 405 laser pulse (photoswitch), the TS disappears in the 488 and appears in the 543 channel. Images show snapshots acquired at the indicated time points. The persistence of the signal in $\mu$ ter310-MBS confirmed the retention of the PTC+ transcripts compared to the PTC- $(A$ and $C, 543$ channels). Upon UPF1 depletion, this retention disappeared, whereas PTC- transcripts remained unaffected ( 543 channel, cf. panels $A, B$ and $C, D$ ). Scale bar, $5 \mu \mathrm{m}$. See also Supplemental Movies S3-S6. (E-G) Mean fluorescence intensity $(+/-$ SEM; $n=10)$ of photoswitched TS in the 543 channel before $(E)$ and after UPF1 knockdown $(F, G)$. Decrease of red fluorescence at TS of untreated $\mu \mathrm{wt}-\mathrm{MBS}$ Dendra (orange) and $\mu$ ter310-MBS Dendra (brown) is shown in E. Depletion of UPF1 in $\mu$ ter310-MBS Dendra reduces the RNA retention $(F)$ but has no effect on PTC- transcripts in $\mu$ wt-MBS Dendra $(G)$.

Supplemental Movies S3-S6). Before the photoswitch (pre), the transcription sites were only visible in the green channel (black arrows in the 488 channel). After the $405-\mathrm{nm}$ activation pulse (photoswitch), only the converted TS appeared in the red channel at the same position (red arrow in the 543 channel). The red signal was then followed over time and quantified (Fig. 6E-G). The recovery of the green TS signal in the 488 channel was also evident, confirming that the reporter genes were still being transcribed. Consistent with our previous observations, the PTC+ transcripts persisted longer at the TS compared to the PTC- transcripts (Fig. 6, cf. panels A and C, 543 channels). This retention of PTC+ transcripts disappeared after depletion of UPF1 (Fig. 6, cf. panels A and B, 543 channels). After $12 \mathrm{~min}$, the $\mu$ ter310-MBS-Dendra showed approximately twofold more Dendra signal retained at the TS than the $\mu w t-M B S-D e n d r a$. These results confirmed that PTC+ release from the transcription site was impaired after synthesis of the MBS (Fig. 6E). Upon UPF1 knockdown, 
the release kinetics of PTC+ transcripts became similar to those of PTC- transcripts (Fig. 6, cf. panels F with E and G). These results, together with the actinomycin D treatment and the UPF1 FRAP, confirmed that a UPF1-dependent PTCspecific anchoring mechanism exists that impairs the dispersion of transcripts from the TS. Furthermore, for $\mu w t-M B S$, UPF1 depletion did not show any changes in retention (Fig. 6G), supporting the effect of UPF1 on elongation (Supplemental Fig. S4B).

\section{SMG6 and UPF1 are physically associated with Ig- $\mu$ transcription sites}

Based on the observations that UPF1 and SMG6 were required for the retention of PTC containing Ig- $\mu$ pre-mRNAs, we surmised that UPF1 and SMG6 may be physically associated with the transcription machinery despite evidence that the localization of SMG6 and UPF1 at steady-state levels are mostly cytoplasmic (Lykke-Andersen et al. 2000). However, SMG5, SMG6, and SMG7 have been reported to shuttle to the nucleus (Ohnishi et al. 2003), similar to UPF1 whose localization in the nucleus was detected upon inhibition of the nuclear export machinery (Mendell et al. 2002). To date, it is not clear what purpose such shuttling has for NMD. However, there is evidence linking UPF1 to DNA stability pathways closely related to DNA replication, and UPF1 has been shown to localize to sites of DNA damage after $\gamma$ irradiation (Azzalin and Lingner 2006b). Both SMG6 and UPF1 have been found in chromatin fractions, and both appear to play a role in the regulation of telomere-associated RNA (Azzalin et al. 2007). To test whether these two factors could associate with the mini $\mu$ transcription sites in $\mu$ wt-MBS and $\mu$ ter310-MBS cells, we performed chromatin immunoprecipitation (ChIP). Chromatin from both cell lines was immunoprecipitated with an anti-UPF1 goat antibody, an anti-SMG6 rabbit antibody, or an anti-RNA polymerase II mouse antibody as a positive control. Normal goat, rabbit, and mouse IgG were used as negative controls, respectively. The immunoprecipitates were then analyzed by RT-qPCR, detecting two different regions of the mini $\mu$ gene, the GAPDH gene and the $18 \mathrm{~S}$ rDNA encoding region. As shown in Figure 7, the anti-Pol II ChIP is enriched in RNA polymerase II-transcribed genes compared to the RNA polymerase I-transcribed region (18S
rDNA) as expected. In the precipitates of the anti-UPF1 and the anti-SMG6 antibodies, DNA from both PTC+ and PTC - mini $\mu$ reporter genes, as well as from GAPDH, was enriched, whereas $18 \mathrm{~S}$ rDNA was significantly less enriched, similar to the result obtained with the anti-Pol II antibody. Treatment of the crosslinked cell lysates with RNase A or actinomycin D prior to immunoprecipitation did not reduce the extent of precipitated DNA (data not shown), suggesting that the association with UPF1 and SMG6 are not RNA-mediated. The similarity of the enrichment patterns obtained with the anti-UPF1, anti-SMG6, and anti-Pol II antibodies might indicate a physical association of UPF1 and SMG6 with the polymerase II transcription machinery, irrespective of the presence of a PTC, consistent with a previous study showing coimmunoprecipitation of UPF1 and UPF2 with the CTD of polymerase II (Iborra et al. 2004b). 
Taken together, the live-cell analyses and the ChIP assays indicate that the NMD factors SMG6 and UPF1 are present at the transcription site of the mini $\mu$ genes, where both play an important function in retaining the PTC+ transcripts at the TS, and in particular, UPF1 seems to participate in regulating the transcription rate of the WT mini $\mu$ RNA.

\section{DISCUSSION}

We were able to analyze the dynamics at the TS of two mRNAs that differ by only one single nucleotide: a $G$ to $T$ point mutation in the mini $\mu$ reporter gene that changes codon 310 from glycine to a premature translation termination codon which truncates the Ig- $\mu$ ORF. As a consequence, the PTC+ mRNA is recognized and degraded by the NMD pathway (Fig. 1; Supplemental Fig. S2A). Consistent with earlier reports (Muhlemann et al. 2001; Buhler et al. 2005), we show here that, in addition to their disappearance in the cytoplasm, the transcriptional and post-transcriptional dynamics of the PTC+ transcripts at the TS were also affected, suggesting that the PTC can be recognized during its synthesis. We detected more PTC+ transcript at the TS compared to PTC- transcript (Fig. 1) and highlighted that these PTC+ transcripts were mostly unspliced (Fig. 2), paralleling previous observations of PTC-dependent pre-mRNA accumulation from Ig- $\mu$ alleles in mouse hybridoma cells (Muhlemann et al. 2001), Ig- $\kappa$ genes in B lymphocytes (Lozano et al. 1994; Aoufouchi et al. 1996), TCR- $\beta$ minigenes expressed in HeLa cells (Muhlemann et al. 2001), and from minute virus of mice (MVM) (Gersappe et al. 1999). We demonstrated by two different live cell-imaging approaches that $\sim 20 \%-25 \%$ of the PTC+ RNA at the TS was immobile, i.e., not released from the TS during the course of our experiments (Figs. 3, 6). This retention of the RNA was not observed with the PTC- version of the mini $\mu$ reporter (Figs. 3, 6) and was dependent on the presence of the two essential NMD factors, SMG6 and UPF1 (Figs. 4-6). Finally, we found both SMG6 and UPF1 to be physically associated with the mini $\mu$ encoding chromatin in both $\mu$ ter310-MBS and $\mu$ wt-MBS (Fig. 7). The association of SMG6 and UPF1 with both versions of the mini $\mu$ gene and with the GAPDH ORF suggests that these proteins can act locally during polymerase II-driven transcription.

Although UPF1 associates with both the PTC+ and the PTC - mini $\mu$ genes, it is intriguing that its depletion affects the dynamics of the PTC+ and PTC- transcripts at the TS differently: loss of retention of PTC+ transcripts versus more rapid elongation of PTC- transcripts (Fig. 5; Supplemental Fig. S4). These different outcomes may reflect a differential modification of UPF1 at PTC+ and PTC - mini $\mu$ genes, for example, differences in its phosphorylation status. We tried to address this by carrying out ChIP with an anti-phospho(S/T)Q antibody that recognizes phosphorylated UPF1 as its main target. However, we found that this antibody was not suitable for ChIP (data not shown).
UPF1's presence on the chromatin could reduce the elongation rate by an unknown mechanism, for instance, by an RNA surveillance process prior to PTC recognition (Miriami et al. 2004). PTC recognition could subsequently trigger UPF1 phosphorylation/dephosphorylation and recruit other factors that would reduce transcription speed. Such a hypothesis could explain why an increase in transcription elongation was not observed with PTC + mini $\mu$ after depletion of UPF1. In contrast to UPF1, knockdown of SMG6 did not affect the transcription elongation rate of PTCtranscripts. However, for the retention of PTC+ RNA, both UPF1 and SMG6 are necessary.

After transcription, most normal nascent RNAs are released by transcription termination and/or poly(A) site cleavage, and then they are free to diffuse away in the nucleus. In the case of the retained PTC + mini $\mu$ RNA, $3^{\prime}$ end processing or transcription termination could be impaired, leading to the retention of nascent RNA still attached to the polymerase, or the nascent RNA could be released by $3^{\prime}$ end processing or termination but cannot leave the site because its diffusion is inhibited. The result of the actinomycin D experiment (Fig. 1D) argues against the former hypothesis, because actinomycin D-induced polymerase stalling would be expected to retain both the nascent PTC+ and WT transcripts similarly. Instead, our data suggests that the PTC+ transcripts were retained after detaching from the polymerase, which could involve an active anchoring mechanism, perhaps association with a large complex that prevents RNA diffusion. The mechanism of this retention remains to be determined. Of note, retention of improperly processed transcripts at the TS has also been observed in murine erythroleukemia cells expressing $\beta$-globin genes defective in splicing or $3^{\prime}$ end formation (Custodio et al. 1999) and in yeast with transcripts that fail to acquire a poly(A) tail (Hilleren et al. 2001; Dower et al. 2004; Dunn et al. 2005), but it has not been investigated whether these effects also involve NMD factors. A very recent investigation of the in vivo kinetics of RNA polymerase II in human U2OS cells provided evidence for a TS retention of polyadenylated transcripts until the completion of splicing (Brody et al. 2011), a mechanism that could account for the retention of the PTC+ mini $\mu$ transcripts observed in our experiments.

Most intriguingly, we detected by FISH almost exclusively unspliced and hardly any spliced PTC+ transcripts at the TS (Fig. 2), suggesting that the retained RNA observed in the FRAP and photoconversion experiments represented mainly pre-mRNA. The use of a mixture of probes targeting every exon-exon junction should have revealed even partially spliced mini $\mu$ RNA. The near absence of even partially spliced PTC+ mRNA at the TS and in the entire cell argues for a direct inhibition of splicing rather than for a faster clearance of the processed transcripts or a retention of fully processed mRNAs that interfere with splicing of ensuing nascent transcripts in trans. The PTC specificity of this apparent splicing inhibition and its dependence on the NMD factors SMG6 and UPF1 
further imply the involvement of translation or another kind of ORF assessment capable of recognizing the PTC. However, a mechanism capable of reading the ORF of a transcript prior to the removal of its introns is conceptually difficult to conceive. Nonetheless, evidence for the existence of such a putative stop codon-mediated suppression of splicing (SOS) mechanism has been reported ( $\mathrm{Li}$ et al. 2002; Kamhi et al. 2010), but the authors claimed that this SOS was distinct from NMD because it was not affected by translation inhibition or UPF1 knockdown (Wachtel et al. 2004). Therefore, it is currently unclear if SOS and the PTC-specific, SMG6- and UPF1-dependent pre-mRNA retention described here are mechanistically related. The detected physical association of SMG6 and UPF1 with the mini $\mu$ gene (Fig. 7) further supports the existence of a mechanism capable of PTC recognition inside the nucleus directly at the TS. Alternatively, the apparently PTC-specific inhibition of pre-mRNA splicing could be induced by a cyto-nuclear feedback signal triggered by PTC recognition during translation in the cytoplasm. Our data would be consistent with such a cyto-nuclear feedback model, but the nature of this putative feedback signal and whether it would be allele-specific or also target coexpressed PTC- transcripts is currently not known.

Several reports had previously identified different nuclear effects in response to the premature truncation of the ORF in a gene, but the interpretation of the results from these mainly biochemical approaches remained ambiguous and controversial. Our utilization of live cell-imaging techniques for the first time has provided kinetic information about the different behavior of PTC+ and PTC - transcripts at the TS and has revealed the specific retention of mainly unspliced PTC+ mini $\mu$ RNA at the TS. Novel imaging approaches that follow the specific fates of PTC+ and PTCtranscripts in the same cell in real time will provide the next step to dissect the mechanism of nuclear-associated NMD and mRNA quality control pathways in general. Although many open questions with regard to the underlying mechanism still remain to be solved, the results presented here solidify the evidence for a quality control step spatially associated with transcription and document a role for the NMD factors UPF1 and SMG6 in differential regulation of transcription, splicing, and transcript release.

\section{MATERIALS AND METHODS}

\section{Generation of plasmids}

To generate $\mathrm{p} \beta \operatorname{mini} \mu \mathrm{A} 1-24 \mathrm{xMS} 2 \mathrm{WT}$ and $\mathrm{p} \beta \operatorname{mini} \mu \mathrm{A} 1-24 \mathrm{xMS} 2$

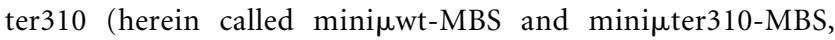
respectively), the $\mathrm{p} \beta \operatorname{mini} \mu \mathrm{WT}$ and ter310 plasmids (Buhler et al. 2004) were modified as follows: (1) The poly(A) signal 100 nucleotides downstream from the stop codon was mutated by sitedirected mutagenesis using primers om151 (AGTGAGATGTTGCA TTTTATAAAAATTAGATATCAAAAAAATCCATTCAAACGTCAC TGG) and om152 (CCAGTGACGTTTGAATGGATTTTTTTGATㅁT
CTAATTTTTATAAAATGCAACATCTCACT; changed nucleotides underlined), and (2) the BamH1-BglII fragment of pSL24 (a gift from Edouard Bertrand), which consists of 24 MS2 binding sites, was inserted into the BamH1 site located in the 3' UTR 161 nucleotides downstream from the stop codon. The sequences of the entire coding regions and 3' UTRs of both plasmids were verified by sequencing.

To generate MCP-YFP and MCP-Dendra2 lentivirus vectors, a PCR fragment corresponding to an NLS-HA-MCP-YFP was generated from the plasmid pMS2-YFP (Fusco et al. 2003), using primers to add an nuclear localization signal on the $\mathrm{C}$ terminus of the construct (5' NLS-NotI: GCGCGCGGCGGCCGCCATGGGCCC AAAAAAGAAAAGAAAAGT TGGCTACCC; 3' YFP-ClaI: GCGCG CGATCGATTTACTTGTACAGCTCGT CCATGCC). The PCR fragment was cut with NotI and ClaI and cloned into the pHAGE-UbcRIG lentiviral vector (a gift from Gustavo Mostoslavsky), from which the DsRed-IRES-GFP fragment had been excised using NotI and ClaI.

From the plasmid MCP-Dendra2 (a gift from Xavier Darzacq), a PCR fragment corresponding to Dendra2 was generated using primers to add XbaI and ClaI restriction sites (XbaI-Dendra2-fwd: GCGCGCGCTCTAGAATGAAC ACCCCGGGAATTAACCTGATC; ClaI-stop-dendra2-rev: GCGCGCGCAT CGATTTACCACACCTGG CTGGGCAGGGGGCTGTAG). The PCR fragment was cut using $\mathrm{XbaI}$ and $\mathrm{ClaI}$ and cloned into the previously generated pHAGEUbc-NLS-MCP-YFP after removal of the YFP fragments by the same restriction enzymes.

\section{Cell lines}

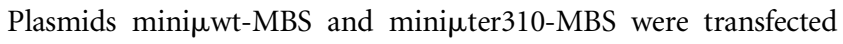
into U2OS cells, selected with G418 for stable integration, and single colonies were isolated after $\sim 3$ wk and expanded, resulting in mono- and biclonal cell lines. From all monoclonal cell lines, those with a single integration site of reporter genes (tested by FISH) were selected for further analysis, which involved testing mini $\mu$ mRNA expression, relative mini $\mu$ gene copy numbers by RT-qPCR, and Southern blotting. To stably express MCP-YFP or MCP-Dendra2, we generated lentivirus vectors to drive expression of the MCP fusions by the Ubiquitin C promoter (UbC). The resulting viruses, generated in $293 \mathrm{~T}$ cells, were used to infect monoclonal $\mu \mathrm{wt}-\mathrm{MBS}$ and $\mu$ ter310-MBS cell lines according to standard protocols.

\section{RNA FISH}

The probes used were a mix of 20mers of ssDNA bearing one Cy3 or Cy5 fluorophore (GE Healthcare-Amersham) to each end (for probe sequences, see Supplemental Materials and Methods). Cells were plated the day before onto coverslips and grown in DMEM low glucose, $10 \%$ FBS, $1 \%$ pen/strep. Cells were briefly washed in PBS, then fixed in $4 \%$ paraformaldehyde for $20 \mathrm{~min}$ at room temperature, washed $5 \mathrm{~min}$ in PBS, and stored in $70 \%$ ethanol at $4^{\circ} \mathrm{C}$. Prior to hybridization, cells were permeabilized for $10 \mathrm{~min}$ in $0.5 \%$ triton X100 in PBS, then washed in PBS for $10 \mathrm{~min}$, and incubated for $10 \mathrm{~min}$ in prehybridization (pre-hyb) solution $(10 \%$ formamide, $2 \times$ SSC, $2 \mathrm{mg} / \mathrm{mL}$ BSA, $0.2 \mathrm{mg} / \mathrm{mL}$ E. coli tRNA, 0.2 $\mathrm{mg} / \mathrm{mL}$ sheared salmon sperm DNA, 10\% dextran sulfate). Hybridization was performed overnight in pre-hyb solution supplemented with $10 \mathrm{ng}$ total DNA probe per coverslip. Coverslips were then washed twice for $20 \mathrm{~min}$ at $37^{\circ} \mathrm{C}$ with pre-hyb solution, followed by $10 \mathrm{~min}$ at room temperature in $2 \times \mathrm{SSC}$, and $10 \mathrm{~min}$ at room temperature in PBS. DNA was counterstained with DAPI $(0.5 \mathrm{mg} / \mathrm{L}$ 
in PBS). After a final wash in PBS, coverslips were mounted on slides using ProLong gold reagent (Invitrogen).

\section{Drug treatment}

Cells were plated on coverslips the day before and then treated with $5 \mu \mathrm{g} / \mathrm{mL}$ actinomycin D (Sigma, A9415) for 1, 2, 3, 4, and $5 \mathrm{~min}$ before fixation for RNA FISH.

\section{Wide-field microscope for fixed-cell imaging}

Images were acquired with an Olympus BX61 (Olympus) microscope equipped with an X-cite 120 PC mercury lamp (EXFO), a PlanApo oil $60 \times, 1.4$ NA objective (Olympus), and a CoolSnap HQ camera (Photometrics). Digital images were acquired with DAPI (filter set \#31000) and Cy3 (filter set \#41007) (Chroma Technology) as $3 \mathrm{D}$ image series (stacks) of 21 images taken with a $\mathrm{Z}$ step size of $0.2 \mu \mathrm{m}$ using IPLab software (Windows v3, BD Biosciences). Images were shown as maximal projections.

\section{Confocal microscopes for live-cell imaging}

FRAP was performed on Zeiss LSM 5 Live with DuoScan at Janelia Farm, HHMI, and later with the same machine at the Analytical Imaging Facility at Albert Einstein College of Medicine, with a Plan Apochromat oil $63 \times \mathrm{X}, 1.4$ NA objective (Jena) and a 489-nm laser. The microscope is equipped with a heated motorized stage and with a large heated chamber (Zeiss), allowing stable long-term acquisition on live cells. For live-cell imaging, cells were plated the day before on a MatTek 35-mm petri dish (P35G-1.5-14C, MatTek Corporation) in DMEM low glucose, $10 \%$ FBS, $1 \%$ pen/strep. Prior to experiments, the cells were washed once, and the medium was replaced with warm Leibovitz L-15 10\% FBS without phenol red.

\section{Wide-field microscope for live-cell imaging}

Photoconversion was performed on an Olympus IX-81 inverted microscope with a UApo $100 \times, 1.4$ NA objective (Olympus) driven by MetaMorph version 7.6 (Molecular Devices). The system was customized in the laboratory to include laser illumination (see details below). For live-cell imaging, cells were plated on a $0.17-\mathrm{mm}$ black delta $\mathrm{T}$ dish (Bioptechs). A constant temperature of $37^{\circ} \mathrm{C}$ was maintained throughout the experiment using a heated lid and objective heater (Bioptechs). To avoid photoconversion of new green signal into red during 488 acquisitions, we used low laser power, and we reduced the 488 acquisitions every 10 frames.

\section{Photoconversion with the wide-field microscope}

A 300 mW Argon Ion 488-nm laser (Lasermodel 800AM; National Laser) and a $1.5 \mathrm{~mW}$ Helium Neon 543-nm laser (model 25-LGR193; Melles Griot) were set up for wide-field illumination and a $100 \mathrm{~mW}$ diode 405-nm laser (model Cube 405-100C; Coherent) was set up for point illumination during photoconversion. Images were acquired using a Cascade 512 EM-CCD camera (Photometrics) equipped with a DualView (Dual-View with model OI-11 dual-color filter set; Photometrics) to acquire simultaneously in the 488 and 543 channels using each half of the camera chip. Filter set used for imaging and photoconversion: dual 488/543 filter set (model NF01-488/543 emission filter with Chroma Technology model Z405/488/543rpc beam splitter; Semrock) and 405 filter set (model NF03-405E emission filter with Chroma Technology model Z405/488/543rpc beam splitter; Semrock). The cells were positioned in the $\mathrm{z}$-axis using a MS-2000-XYLE-PZ piezo-top stage (Applied Scientific Imaging).

\section{RNAi-mediated SMG6 and UPF1 knockdown}

Knockdown of SMG6 was induced by transfection of pSUPERpuro plasmids target sequence 10 in human SMG6 (Eberle et al. 2009). Knockdown of human UPF1 was induced by transfection of two pSUPERpuro plasmids targeting different sequences of the UPF1 mRNA (Paillusson et al. 2005). A control shRNA (scr-shRNA) encoding a scrambled sequence with no predicted target in human cells was used as a negative control. Knockdown levels were analyzed at the protein level by Western blotting and at the RNA level by RT-qPCR.

\section{Western blotting}

For Western blotting, whole cell extracts (WCE) were loaded on an $8 \%$ SDS-PAGE, and proteins were transferred onto PVDF membranes. The membranes were probed overnight at $4^{\circ} \mathrm{C}$ with primary antibodies (dilutions: 1:400 rabbit anti-hSMG6 (Eurogentec); 1:5000 mouse anti-Tyr-Tubulin (TUB-1A2, IgG3 isotype; Sigma), and 1:1000 goat anti-hUPF1 (anti-RENT1, A300-036A; Bethyl Laboratories); and for $1 \mathrm{~h}$ at room temperature with secondary antibodies donkey anti-mouse IRDye 800 (\#610-732-124; Rockland Immunochemicals, Inc.), donkey anti-goat IRDye 700 (\#605-730-125; Rockland Immunochemicals, Inc.), and goat-anti-rabbit IRDye 800 (\#926-32211; Li-COR Biosciences), all diluted 1:15,000. The signals were detected and analyzed using the Odyssey Infrared Imaging System (LI-COR Biosciences).

\section{Chromatin immunoprecipitation (ChIP)}

ChIP was performed following the protocol from the EZ-Magna ChIP-G (\#17-409; Millipore). Briefly, cells were grown in 15-cm culture dishes until $90 \%$ confluent $\left(\sim 1 \times 10^{7}\right.$ cells). After in vivo crosslinking and lysis, the lysate was sonicated. An aliquot of the sheared chromatin was analyzed by gel electrophoresis to verify that the DNA was sheared into fragments of 200-500 bp. The DNA was aliquoted, and $1 \times 10^{6}$-cell equivalents of lysate were used for each IP. Prior to IP, $1 \%$ of the chromatin was removed to serve as an input control. One $\mu \mathrm{g} / \mathrm{IP}$ of anti-Pol II 4H8 (\#05-623B) and anti-mouse (\#12-371B) provided in the kit were used. Ten $\mu \mathrm{g} / \mathrm{IP}$ of anti-UPF1 (anti-RENT1, A300-036A; Bethyl Laboratories) and anti-SMG6 (custom-made peptide antibody from Eurogentec) were used. Ten $\mu \mathrm{g} / \mathrm{IP}$ of normal goat and rabbit IgG (sc-2028 and sc-2027; Santa Cruz Biotech) were used as control sera. Incubation was performed overnight at $4^{\circ} \mathrm{C}$ with rotation. After washing and elution, the purified DNA was analyzed by qPCR where reactions were carried out in triplicate using a fixed amount of template DNA. The ChIP results obtained by four independent replicate experiments are represented by the selective enrichment of a chromatin fraction being defined as a ratio of precipitated over input and then normalized to the relative enrichment of genomic GAPDH DNA.

\section{Real time-quantitative PCR}

The RNA was isolated using the Absolutely RNA RT-PCR Miniprep kit (Stratagene). Total RNA ( $1 \mu \mathrm{g})$ was reverse-transcribed in $20 \mu \mathrm{l}$ 
StrataScript 6.0 RT buffer in the presence of $1 \mathrm{mM}$ dNTPs, $300 \mathrm{ng}$ random hexamers, $40 \mathrm{U}$ RNasin (Dundee Life Sciences), and $50 \mathrm{U}$ StrataScript 6.0 reverse transcriptase (Stratagene) according to manufacturer's protocol. For real-time PCR, Brillant II Fast QPCR Master Mix (Stratagene), a commercial TaqMan assay from Applied Biosystems (cat. \#431-9413E), and cDNA corresponding to $24 \mathrm{ng}$ reverse-transcribed RNA were used to measure $18 \mathrm{~S}$ rRNA. Mini $\mu$ mRNA, UPF1 mRNA, and SMG6 mRNA levels were measured using $800 \mathrm{nM}$ of each primer and $200 \mathrm{nM}$ TaqMan probe (see above). The Rotor-Gene 6000 (Corbett Research) was used for PCR and fluorescence read. Relative RNA levels were calculated from CT values according to the $\Delta \mathrm{CT}$ method, and relative mini $\mu$ mRNA, UPF1 mRNA, and SMG6 mRNA levels were normalized to $18 \mathrm{~S}$ rRNA levels. For the TaqMan probes used, see Supplemental Materials and Methods.

\section{SUPPLEMENTAL MATERIAL}

Supplemental material is available for this article.

\section{ACKNOWLEDGMENTS}

We thank Alexandra Paillusson and Karin Schranz for generating monoclonal cell lines and Xiuhua Meng for help with FISH. We further thank the Genomic Imaging Facility at Albert Einstein for the DNA FISH and Edouard Bertrand (IGMM), Xavier Darzacq (ENS Paris), and Gustavo Mostoslavsky (Boston University School of Medicine) for providing valuable reagents. This work was supported by NIH GM86217 to R.H.S. and by a starting grant from the European Research Council (\#207419) and grants from the Swiss National Science Foundation (\#3100A0-102159; \#31003A-113878; \#31003A-127614) to O.M.

Author contributions: V.d.T., O.M., and R.H.S. conceived and designed the experiments. V.d.T. performed all the microscopy work and generated most of the data (Figs. 1-6, Supplemental Figs. S1, S3, S4). P.N. (Figs. 4a, 5a, 7 and Supplemental Fig. S2), and R.Z.O. (Supplemental Fig. S2) contributed with biochemical analyses. V.d.T., P.N., O.M., and R.H.S. analyzed and interpreted the data and prepared the manuscript.

Received July 6, 2011; accepted August 30, 2011.

\section{REFERENCES}

Amrani N, Sachs MS, Jacobson A. 2006. Early nonsense: mRNA decay solves a translational problem. Nat Rev Mol Cell Biol 7: 415-425.

Aoufouchi S, Yelamos J, Milstein C. 1996. Nonsense mutations inhibit RNA splicing in a cell-free system: Recognition of mutant codon is independent of protein synthesis. Cell 85: 415-422.

Azzalin CM, Lingner J. 2006a. The double life of UPF1 in RNA and DNA stability pathways. Cell Cycle 5: 1496-1498.

Azzalin CM, Lingner J. 2006b. The human RNA surveillance factor $\mathrm{UPF} 1$ is required for $\mathrm{S}$ phase progression and genome stability. Curr Biol 16: 433-439.

Azzalin CM, Reichenbach P, Khoriauli L, Giulotto E, Lingner J. 2007. Telomeric repeat containing RNA and RNA surveillance factors at mammalian chromosome ends. Science 318: 798-801.

Belgrader P, Cheng J, Zhou X, Stephenson LS, Maquat LE. 1994. Mammalian nonsense codons can be cis effectors of nuclear mRNA half-life. Mol Cell Biol 14: 8219-8228.
Bertrand E, Chartrand P, Schaefer M, Shenoy SM, Singer RH, Long RM. 1998. Localization of ASH1 mRNA particles in living yeast. Mol Cell 2: 437-445.

Bhalla AD, Gudikote JP, Wang J, Chan WK, Chang YF, Olivas OR, Wilkinson MF. 2009. Nonsense codons trigger an RNA partitioning shift. J Biol Chem 284: 4062-4072.

Bohnsack MT, Regener K, Schwappach B, Saffrich R, Paraskeva E, Hartmann E, Gorlich D. 2002. Exp5 exports eEF1A via tRNA from nuclei and synergizes with other transport pathways to confine translation to the cytoplasm. EMBO J 21: 6205-6215.

Brody Y, Neufeld N, Bieberstein N, Causse SZ, Bohnlein EM, Neugebauer KM, Darzacq X, Shav-Tal Y. 2011. The in vivo kinetics of RNA polymerase II elongation during co-transcriptional splicing. PLoS Biol 9: e1000573. doi: 10.1371/journal.pbio.1000573.

Brogna S, Sato TA, Rosbash M. 2002. Ribosome components are associated with sites of transcription. Mol Cell 10: 93-104.

Buhler M, Wilkinson MF, Muhlemann O. 2002. Intranuclear degradation of nonsense codon-containing mRNA. EMBO Rep 3: 646-651.

Buhler M, Paillusson A, Muhlemann O. 2004. Efficient downregulation of immunoglobulin $\mu$ mRNA with premature translation-termination codons requires the $5^{\prime}$-half of the VDJ exon. Nucleic Acids Res 32: 3304-3315.

Buhler M, Mohn F, Stalder L, Muhlemann O. 2005. Transcriptional silencing of nonsense codon-containing immunoglobulin minigenes. Mol Cell 18: 307-317.

Buhler M, Steiner S, Mohn F, Paillusson A, Muhlemann O. 2006. EJCindependent degradation of nonsense immunoglobulin- $\mu$ mRNA depends on 3' UTR length. Nat Struct Mol Biol 13: 462-464.

Carter MS, Li S, Wilkinson MF. 1996. A splicing-dependent regulatory mechanism that detects translation signals. EMBO J 15: 5965-5975.

Chan WK, Huang L, Gudikote JP, Chang YF, Imam JS, MacLean JA II, Wilkinson MF. 2007. An alternative branch of the nonsensemediated decay pathway. EMBO J 26: 1820-1830.

Cheng J, Maquat LE. 1993. Nonsense codons can reduce the abundance of nuclear mRNA without affecting the abundance of pre-mRNA or the half-life of cytoplasmic mRNA. Mol Cell Biol 13: 1892-1902.

Chiu SY, Lejeune F, Ranganathan AC, Maquat LE. 2004. The pioneer translation initiation complex is functionally distinct from but structurally overlaps with the steady-state translation initiation complex. Genes Dev 18: 745-754.

Custodio N, Carmo-Fonseca M, Geraghty F, Pereira HS, Grosveld F, Antoniou M. 1999. Inefficient processing impairs release of RNA from the site of transcription. EMBO J 18: 2855-2866.

Darzacq X, Singer RH, Shav-Tal Y. 2005. Dynamics of transcription and mRNA export. Curr Opin Cell Biol 17: 332-339.

Darzacq X, Shav-Tal Y, de Turris V, Brody Y, Shenoy SM, Phair RD, Singer RH. 2007. In vivo dynamics of RNA polymerase II transcription. Nat Struct Mol Biol 14: 796-806.

Dietz HC, Kendzior RJ Jr. 1994. Maintenance of an open reading frame as an additional level of scrutiny during splice site selection. Nat Genet 8: 183-188.

Dower K, Kuperwasser N, Merrikh H, Rosbash M. 2004. A synthetic A tail rescues yeast nuclear accumulation of a ribozyme-terminated transcript. RNA 10: 1888-1899.

Dunn EF, Hammell CM, Hodge CA, Cole CN. 2005. Yeast poly(A)binding protein, Pab1, and PAN, a poly(A) nuclease complex recruited by Pab1, connect mRNA biogenesis to export. Genes Dev 19: $90-103$.

Eberle AB, Stalder L, Mathys H, Orozco RZ, Muhlemann O. 2008. Posttranscriptional gene regulation by spatial rearrangement of the 3' untranslated region. PLoS Biol 6: e92. doi: 10.1371/journal. pbio.0060092.

Eberle AB, Lykke-Andersen S, Muhlemann O, Jensen TH. 2009. SMG6 promotes endonucleolytic cleavage of nonsense mRNA in human cells. Nat Struct Mol Biol 16: 49-55.

Fusco D, Accornero N, Lavoie B, Shenoy SM, Blanchard JM, Singer RH, Bertrand E. 2003. Single mRNA molecules demonstrate probabilistic movement in living mammalian cells. Curr Biol 13: 161-167. 
Gersappe A, Burger L, Pintel DJ. 1999. A premature termination codon in either exon of minute virus of mice $\mathrm{P} 4$ promoter-generated pre-mRNA can inhibit nuclear splicing of the intervening intron in an open reading frame-dependent manner. J Biol Chem 274: 22452-22458.

Gurskaya NG, Verkhusha VV, Shcheglov AS, Staroverov DB, Chepurnykh TV, Fradkov AF, Lukyanov S, Lukyanov KA. 2006. Engineering of a monomeric green-to-red photoactivatable fluorescent protein induced by blue light. Nat Biotechnol 24: 461-465.

Hilleren P, McCarthy T, Rosbash M, Parker R, Jensen TH. 2001. Quality control of mRNA $3^{\prime}$-end processing is linked to the nuclear exosome. Nature 413: 538-542.

Huntzinger E, Kashima I, Fauser M, Sauliere J, Izaurralde E. 2008. SMG6 is the catalytic endonuclease that cleaves mRNAs containing nonsense codons in metazoan. RNA 14: 2609-2617.

Iborra FJ, Jackson DA, Cook PR. 2001. Coupled transcription and translation within nuclei of mammalian cells. Science 293: 1139-1142.

Iborra FJ, Escargueil AE, Kwek KY, Akoulitchev A, Cook PR. 2004a. Molecular cross-talk between the transcription, translation, and nonsense-mediated decay machineries. J Cell Sci 117: 899-906.

Iborra FJ, Jackson DA, Cook PR. 2004b. The case for nuclear translation. J Cell Sci 117: 5713-5720.

Ishigaki Y, Li X, Serin G, Maquat LE. 2001. Evidence for a pioneer round of mRNA translation. mRNAs subject to nonsense-mediated decay in mammalian cells are bound by CBP80 and CBP20. Cell 106: $607-617$.

Isken O, Maquat LE. 2007. Quality control of eukaryotic mRNA: Safeguarding cells from abnormal mRNA function. Genes Dev 21: $1833-1856$.

Ivanov PV, Gehring NH, Kunz JB, Hentze MW, Kulozik AE. 2008. Interactions between UPF1, eRFs, PABP, and the exon junction complex suggest an integrated model for mammalian NMD pathways. EMBO J 27: 736-747.

Kamhi E, Raitskin O, Sperling R, Sperling J. 2010. A potential role for initiator-tRNA in pre-mRNA splicing regulation. Proc Natl Acad Sci 107: 11319-11324.

Kessler O, Chasin LA. 1996. Effects of nonsense mutations on nuclear and cytoplasmic adenine phosphoribosyltransferase RNA. Mol Cell Biol 16: 4426-4435.

Kohler G, Milstein C. 1976. Derivation of specific antibody-producing tissue culture and tumor lines by cell fusion. Eur J Immunol 6: 511-519.

Li B, Wachtel C, Miriami E, Yahalom G, Friedlander G, Sharon G, Sperling R, Sperling J. 2002. Stop codons affect 5 ' splice site selection by surveillance of splicing. Proc Natl Acad Sci 99: 5277-5282.

Lozano F, Maertzdorf B, Pannell R, Milstein C. 1994. Low cytoplasmic mRNA levels of immunoglobulin $\kappa$ light chain genes containing nonsense codons correlate with inefficient splicing. EMBO J 13: 4617-4622.

Lund E, Dahlberg JE. 1998. Proofreading and aminoacylation of tRNAs before export from the nucleus. Science 282: 2082-2085.

Lykke-Andersen J, Shu MD, Steitz JA. 2000. Human Upf proteins target an mRNA for nonsense-mediated decay when bound downstream of a termination codon. Cell 103: 1121-1131.

Matsuda D, Hosoda N, Kim YK, Maquat LE. 2007. Failsafe nonsensemediated mRNA decay does not detectably target eIF4E-bound mRNA. Nat Struct Mol Biol 14: 974-979.

Mendell JT, ap Rhys CM, Dietz HC. 2002. Separable roles for rent1/ hUpf1 in altered splicing and decay of nonsense transcripts. Science 298: 419-422.
Miriami E, Sperling R, Sperling J, Motro U. 2004. Regulation of splicing: The importance of being translatable. RNA 10: 1-4.

Mostoslavsky G, Fabian AJ, Rooney S, Alt FW, Mulligan RC. 2006. Complete correction of murine Artemis immunodeficiency by lentiviral vector-mediated gene transfer. Proc Natl Acad Sci 103: 16406-16411.

Muhlemann O, Mock-Casagrande CS, Wang J, Li S, Custodio N, Carmo-Fonseca M, Wilkinson MF, Moore MJ. 2001. Precursor RNAs harboring nonsense codons accumulate near the site of transcription. Mol Cell 8: 33-43.

Nicholson P, Yepiskoposyan H, Metze S, Zamudio Orozco R, Kleinschmidt N, Muhlemann O. 2010. Nonsense-mediated mRNA decay in human cells: Mechanistic insights, functions beyond quality control, and the double-life of NMD factors. Cell Mol Life Sci 67: 677-700.

Ochi A, Hawley RG, Hawley T, Shulman MJ, Traunecker A, Kohler G, Hozumi N. 1983. Functional immunoglobulin M production after transfection of cloned immunoglobulin heavy and light chain genes into lymphoid cells. Proc Natl Acad Sci 80: 6351-6355.

Ohnishi T, Yamashita A, Kashima I, Schell T, Anders KR, Grimson A, Hachiya T, Hentze MW, Anderson P, Ohno S. 2003. Phosphorylation of hUPF1 induces formation of mRNA surveillance complexes containing hSMG-5 and hSMG-7. Mol Cell 12: 1187-1200.

Paillusson A, Hirschi N, Vallan C, Azzalin CM, Muhlemann O. 2005. A GFP-based reporter system to monitor nonsense-mediated mRNA decay. Nucleic Acids Res 33: e54. doi: 10.1093/nar/gni052.

Pandit S, Wang D, Fu XD. 2008. Functional integration of transcriptional and RNA processing machineries. Curr Opin Cell Biol 20: 260-265.

Rebbapragada I, Lykke-Andersen J. 2009. Execution of nonsensemediated mRNA decay: What defines a substrate? Curr Opin Cell Biol 21: 394-402.

Rehwinkel J, Raes J, Izaurralde E. 2006. Nonsense-mediated mRNA decay: Target genes and functional diversification of effectors. Trends Biochem Sci 31: 639-646.

Singh G, Jakob S, Kleedehn MG, Lykke-Andersen J. 2007. Communication with the exon-junction complex and activation of nonsense-mediated decay by human Upf proteins occur in the cytoplasm. Mol Cell 27: 780-792.

Stalder L, Muhlemann O. 2007. Transcriptional silencing of nonsense codon-containing immunoglobulin $\mu$ genes requires translation of its mRNA. J Biol Chem 282: 16079-16085.

Thompson RE, Larson DR, Webb WW. 2002. Precise nanometer localization analysis for individual fluorescent probes. Biophys J 82: 2775-2783.

Wachtel C, Li B, Sperling J, Sperling R. 2004. Stop codon-mediated suppression of splicing is a novel nuclear scanning mechanism not affected by elements of protein synthesis and NMD. RNA 10: $1740-1750$.

Wang J, Hamilton JI, Carter MS, Li S, Wilkinson MF. 2002a. Alternatively spliced TCR mRNA induced by disruption of reading frame. Science 297: 108-110.

Wang J, Vock VM, Li S, Olivas OR, Wilkinson MF. 2002b. A quality control pathway that down-regulates aberrant T-cell receptor (TCR) transcripts by a mechanism requiring UPF2 and translation. J Biol Chem 277: 18489-18493.

Zhang J, Sun X, Qian Y, Maquat LE. 1998. Intron function in the nonsense-mediated decay of $\beta$-globin mRNA: Indications that pre-mRNA splicing in the nucleus can influence mRNA translation in the cytoplasm. RNA 4: 801-815. 

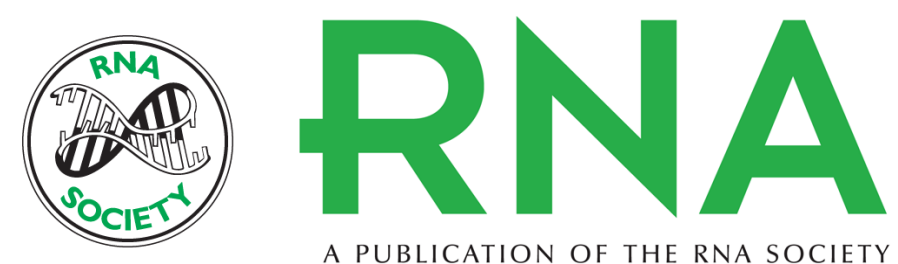

A PUBLICATION OF THE RNA SOCIETY

\section{Cotranscriptional effect of a premature termination codon revealed by live-cell imaging}

Valeria de Turris, Pamela Nicholson, Rodolfo Zamudio Orozco, et al.

RNA 2011 17: 2094-2107 originally published online October 25, 2011

Access the most recent version at doi:10.1261/rna.02918111

Supplemental http://rnajournal.cshlp.org/content/suppl/2011/10/13/rna.02918111.DC1
Material

References This article cites 64 articles, 29 of which can be accessed free at:

http://rnajournal.cshlp.org/content/17/12/2094.full.html\#ref-list-1

\section{License}

Email Alerting Receive free email alerts when new articles cite this article - sign up in the box at the Service top right corner of the article or click here.

\section{IIIII!' Providing Precise Solutions for your research.}

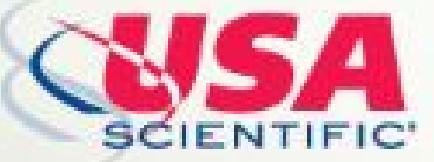

To subscribe to $R N A$ go to:

http://rnajournal.cshlp.org/subscriptions 